\title{
PRIMEIROS SOCORROS E PREVENÇÃO DE ACIDENTES NO AMBIENTE ESCOLAR: INTERVENÇÃO EM UNIDADE DE ENSINO
}

Larissa Graziela Sousa da Silva ${ }^{1}$, Josias Botelho da Costa², Leticia Gemyna Serrão Furtado², Jonatas Bezerra Tavares², José Leandro Diniz Costa²

Objetivo: descrever uma ação educativa com professores do ensino primário e identificar possiveis situações de risco para acidentes. Metodologia: relato de experiência, utilizando a observação e roda de conversa para a coleta de dados. Resultados: construíram-se duas dimensões empíricas, que permitiram constatar que a estrutura observada apresenta fatores de risco para acometimentos e há deficiência no conhecimento sobre o atendimento primário. Conclusão: medidas educativas, envolvidas no diálogo, auxiliam o fortalecimento e aprimoramento da prática preventiva e interventiva na escola, o que aponta a importância da construção de um ambiente escolar seguro.

Descritores: Educação em Saúde, Saúde Escolar, Primeiros Socorros.

\section{FIRST AID AND PREVENTION OF ACCIDENTS IN THE SCHOOL ENVIRONMENT: INTERVENTION IN THE EDUCATIONAL UNIT}

Objective: To describe an educational action with primary school teachers and to identify possible risky situations for accidents. Methodology: Experience report, using the observation and round table conversation for data collection. Results: two empirical dimensions were set-up, which allowed to verify that the observed structure presents risk factors for IMPAIRMENT, and there is a lack of knowledge about the primary care. Conclusion: educational measures, involved in the dialogue, help strengthen and improve preventive and interventional practice in school and highlights the importance of building a safe school environment. Descriptors: Health Education, School Health, First Aid.

\section{PRIMEROS AUXILIOS Y PREVENCIÓN DE ACCIDENTES EN EL MEDIO AMBIENTE ESCOLAR: INTERVENCIÓN EN UNIDAD DE ENSINO.}

Objetivo: El entorno escolar es uno de lossitiosvulnerables para losaccidentes y loscambiosenel estado de salud de losniños y los educadores por lo general sonlosprimerosen entrar enacción. En esta perspectiva, el objetivo delestudio es describir una actividad educativa conlos maestros de primaria y para identificar posiblessituaciones de riesgo de accidentes. Adoptado lametodologíadescriptivo de naturalezacualitativa, mediante laobservación y larueda de conversación para larecolección de datos. El análisis mediante encuestasenla literatura científica y ladiscusión de losdatos, ayudó a laconstrucción de dos dimensiones empíricas, que ayudó a confirmar que laestructura observada presenta factores de riesgo de deterioro si hay una falta de conocimiento acerca de laatención primaria. Este estudiomostró que las medidas educativas que participanenel diálogo, ayudan a lamejora y elfortalecimiento de lapráctica preventiva y de intervenciónenlaescuela y señalalaimportancia de crearun ambiente escolar seguro.

Descriptores: Educación para la Salud, Escuela de Salud, Primeros Auxilios. 


\section{INTRODUÇÃO}

Com o crescente aumento da violência nas escolas estaduais e municipais de todo o país e as ocorrências de acidentes e alterações no estado de saúde que acometem os estudantes, observa-se a necessidade de abordar o tema Primeiros Socorros em colégios, tendo em vista que a maioria dos professores mostra-se despreparada para oferecer suporte aos alunos em situação de emergência, frente a incidentes que necessitam os primeiros socorros e/ou pronto atendimento ${ }^{(1,2)}$. Além disso, os gestores, professores e diretores necessitam promover um ambiente físico, social e psicológico seguros, visto que os pequeninos tendem a interagir e desenvolver as mais diversas atividades esportivas e motoras ${ }^{(3)}$.

É importante que profissionais de educação física e demais professores participem, periodicamente, de cursos e treinamentos em primeiros socorros e pronto atendimento, para se capacitarem adequadamente, nos aspectos psicológicos, emocionais e técnicos, assim proporcionando maior segurança aos alunos e demais professores da escola.

As escolas e os professores têm um papel importante na promoção da saúde e na prevenção de doenças e acidentes entre crianças e adolescentes, pois são os primeiros a terem contato com a vítima na prestação do primeiro atendimento na escola(3). Dentre essas situações, observa-se como principais e mais comuns, nas escolas, sangramento nasal, desmaio, entorses e luxações, fraturas, cortes e escoriações ${ }^{(3)}$.

$\mathrm{Na}$ grade curricular dos cursos de licenciatura, com poucas exceções, não se faz presente uma disciplina que ensine procedimentos básicos de primeiros socorros; em consequência, os professores não sabem como agir em situações que comprometam a saúde da criança, gerando risco para o estado vital do escolar ${ }^{(4)}$.

Nesse sentido, surgiu o interesse em realizar uma estratégia de educação em saúde voltada para os primeiros socorros na escola. Esse interesse adveio das práticas clínicas no componente curricular Enfermagem em Urgência e Emergência, desenvolvido no bloco I do 4aa ano da graduação de Enfermagem, somado ao contato anterior com o Programa Saúde nas Escolas do Ministério da Saúde. Desse modo, pretendeu-se associar a importância das práticas preventivas dos agravos à saúde com as dificuldades relatadas pelos professores em atender as crianças em casos de emergência.

Diante do exposto, este trabalho tem como objetivo descrever uma ação educativa na escola, referente aos primeiros socorros, com professores do ensino primário, e identificar possiveis situações de risco para acidentes com os escolares. $\mathrm{O}$ estudo teve o intuito, também, de estimular a autonomia dos educadores para os cuidados primários e evitar possíveis agravos, devido às condutas realizadas de forma inadequada.

\section{METODOLOGIA}

Trata-se de um relato de experiência, especificamente, de uma ação educativa desenvolvida com docentes de uma escola municipal de ensino infantil, localizada na cidade de Tucuruí, no estado do Pará. Utilizou-se a observação e roda de conversa para a coleta de dados, sendo realizadas em três etapas:

Etapa 1. Visita ao ambiente escolar e levantamento de problemáticas; Etapa 2. Diálogo com professores e coordenadores, com apresentação da proposta de intervenção e coleta de possíveis temáticas a serem discutidas; e Etapa 3. Execução de atividade educativa.

A primeira etapa orientou este estudo quanto aos aspectos estruturais da escola e às características e disposição observadas dos educandos nesse ambiente; a segunda corroborou para a facilitação e planejamento da intervenção, além da identificação das seguintes temáticas, mediante o diálogo e relato das vivências anteriores dos professores: desmaio, engasgo, fraturas, convulsão, ferimentos e sangramento nasal. A última fase apresentou a discussão das temáticas anteriores, contando com a utilização de recursos audiovisuais, realização de atividades práticas e técnica pedagógica para a avaliação da atividade, com o uso de cartolina e pincel de quadro branco.

A ação educativa somente ocorreu após a autorização da diretora da escola e dos professores presentes. $O$ comitê ético da Universidade Estadual do Pará considerou que, a partir das diretrizes para pesquisas definidas pela resolução CNS/MS 466/12 e suas complementares, a proposta de ação educativa não necessita de submissão para apreciação ética ao comitê, por se tratar de relato de experiência dos próprios coautores, com anuência do local e dos participantes onde 
ocorreu o estágio curricular obrigatório, asseguradas as garantias de confidencialidade dos dados.

Para a análise e discussão dos dados colhidos, utilizou-se a literatura, com a construção de duas dimensões empíricas: relação escola $x$ criança e risco de acometimentos e intervenção educativa.

\section{RESULTADOS}

O local de realização da intervenção possui um amplo espaço físico composto por 15 salas de aula, três banheiros masculinos e três banheiros femininos, área de alimentação, copa, biblioteca, sala de atividades lúdicas, sala dos professores, diretoria, secretaria e quadra poliesportiva (que se encontra em processo de construção). A escola atende 696 alunos (335 do sexo masculino e 361 do sexo feminino); 347 estudam no período matutino e 349 no período vespertino, divididos em 30 turmas organizadas de forma paritária: 15 pela manhã e 15 à tarde, que vão desde o pré-escolar até o 5 ㅇ ano do ensino fundamental.

Com relação ao quadro de professores, esses totalizam 47, sendo 30 professores regentes, cinco professores mediadores, nove professores de área (educação física, língua inglesa, ensino religioso e ensino da arte) e três coordenadores, sendo um do ensino infantil, um do ensino fundamental e um coordenador de inclusão. Cada professor regente é responsável por uma turma. Ao considerar o quantitativo de alunos e de turmas, obtém-se uma média de 23,2 alunos por professor regente.

\subsection{Dimensão 1: relação escola x criança e risco de acometimentos}

O ambiente escolar é o espaço em que as crianças passam cerca de um terço de seu tempo. Esse torna-se um ambiente propício à ocorrência de acidentes, porque é o local onde um grande número de crianças e jovens interage, desenvolvendo as mais diversas atividades, mas é também um espaço privilegiado e potencializador. Embora se tenha a percepção que esse meio seja seguro, por se tratar de local responsável pela formação de cidadãos, é um ambiente favorável a acidentes pelo desenvolvimento de diferentes atividades, principalmente as esportistas ${ }^{(1.5)}$.

Nessa perspectiva, o ambiente alvo dessa intervenção foi observado nos diferentes aspectos de sua estrutura e funcionamento, avaliando os pontos que podem ser destacados como propícios para acidentes entre os escolares. Dentre os achados, pode-se destacar que, pela escola ser localizada em um prédio de dois andares, o perigo de quedas de grandes alturas é preocupante; as janelas das salas do segundo andar encontravam-se sem grades ou telas de proteção, o que sugere que crianças, em momentos de aula ou nos intervalos, podem sofrer quedas de uma altura considerável.

O risco de quedas também está presente na escada que dá acesso ao segundo andar da escola. A escada não possui corrimão e/ou grade de proteção, constituindo-se em possível risco no momento de descida das crianças que estudam no segundo andar. Como se trata de uma estrutura de concreto e de uma altura de cerca de $3,5 \mathrm{~m}$, os traumas nesse local podem se apresentar como graves.

3.2. Dimensão 2: intervenção educativa

A terceira etapa desse estudo foi concretizada na realização de uma atividade educativa, contando com a participação de 10 professores. Voltou-se para a discussão de primeiros socorros frente às intercorrências de emergência, elencadas previamente durante o diálogo com o corpo docente escolar

O planejamento e o desenvolvimento da atividade educativa apoiaram-se, teoricamente, no Protocolo de Suporte Básico de Vida(b), enfocando as seguintes temáticas: desmaio, engasgo, fraturas, convulsão, ferimentos e sangramento nasal; e abordando conceitos, possiveis causas e modos de intervenção de primeiros socorros com simulações.

Inicialmente, foi descrita a temática desmaio, e as principais intervenções recomendadas, com descrição prática e dinâmica, incluindo a participação dos professores durante as intervenções. Assim, seguiu-se a mesma metodologia na abordagem dos demais temas: engasgo, fraturas, convulsões, ferimentos e sangramento nasal.

Contudo, ficou evidente no diálogo a presença de insegurança por parte dos professores e o sentimento de estarem fazendo intervenção de forma inadequada, podendo levar ao agravamento da situação ou à exposição desnecessária da criança. As observações nas atividades 
práticas mostraram o pouco conhecimento dos professores sobre as técnicas intervencionistas, no manejo inicial e no acionamento de ajuda de urgência, quando necessário, além de não relacionarem a execução do atendimento com a adoção de posturas corporais adequadas. Os participantes ainda discutiram sobre o contato com secreções e fluidos sanguinolentos, demonstrando que possuem receio e medo de contaminação.

As experiências vivenciadas pelos professores contribuíram para aproximar a discussão de suas realidades e o compartilhamento dessas experiências serviu de base para a avaliação final após a execução da atividade. Essas situações foram descritas em papel cartolina, buscando manejar o debate sobre as intervenções realizadas nas abordagens vividas e como procederiam caso presenciassem novamente as ocorrências, após a participação na atividade dialógica e educativa.

O resultado da avaliação pedagógica foi promissor. Os docentes conseguiram usar dos debates compartilhados no encontro e descreveram suas atuações de forma responsável e cuidadosa. Algumas dúvidas ainda presentes foram esclarecidas; essas se referiam ao acionamento de familiares, tumulto dos escolares e a busca por serviço especializado.

Finalizando o processo de intervenção, foi entregue um estojo de primeiros socorros à direção. Nele continha os materiais recomendados por Brolezi(3), que são: água boricada, solução fisiológica, atadura, gaze e algodão esterilizados, esparadrapo, caixa com luvas de procedimentos e um termômetro. Durante a entrega, foi explicado aos professores a finalidade do uso de cada item e a forma correta de utilizálos.

\section{DISCUSSÃO}

\subsection{Dimensão 1: relação escola $x$ criança e risco de acometimentos}

A influência da estrutura da escola na redução dos acidentes sofridos por crianças no ambiente escolar deve ser considerada na concepção dos prédios em que tais estabelecimentos irão funcionar. A escola, apesar de apresentar uma estrutura que pode ser considerada segura, possui alguns pontos que precisam ser corrigidos. Além disso, o conhecimento dos fatores de risco e dos acometimentos acidentais mais comuns entre escolares, especialmente no ambiente escolar, permite ações e condutas mais pontuais e efetivas na prevenção de tais eventos.

Nesse caminho, diversos achados na literatura têm demonstrado os tipos de acidentes mais prevalentes entre escolares no espaço escolar. Embora a delimitação específica dos acidentes no ambiente educativo não seja satisfatória, pode-se encontrar na literatura alguns estudos que citam acidentes comuns nas escolas, como o sangramento nasal, desmaio, entorses e luxações, fraturas, cortes e escoriações ${ }^{(3)}$.

Ainda descrevem as aulas de educação física como o momento em que incidentes geralmente acontecem. Também, os acidentes com os alunos podem acontecer em outros momentos, como no horário do recreio, na entrada ou na saída da escola(3)

As quedas são apontadas como o agravo mais prevalente e a principal causa de lesões traumáticas cerebrais, com um risco significativo de sequelas crônicas, no ambiente escolar ${ }^{(5)}$. Mesmo que a maioria dos acidentes na escola não necessite de atenção médica, ela tem um índice considerável de eventos acidentais relacionados, em mais de um terço, a esportes e atividades recreativas e, próximo a um terço, resultante de quedas durante outras atividades.

Sendo assim, a segurança do ambiente escolar passa tanto pela estruturação física adequada da escola, quanto pelo preparo dos agentes que atuam no ambiente escolar. Nesse caminho, especulase que o conhecimento sobre primeiros socorros se faz necessário nas diferentes faixas etárias e para indivíduos de diferentes segmentos sociais e profissionais, pois o emprego desses procedimentos pode se fazer necessário para os mais variados grupos de uma população(7). Cabe salientar, portanto, a importância deste estudo, inclusive por abordar situações que fazem parte do cotidiano dos individuos envolvidos, colaborando, assim, com novos conhecimentos e informações significativas para a cultura do "prestar socorro".

\subsection{Dimensão 2: intervenção educativa}

Um estudo realizado com professores ${ }^{(3)}$ verificou que os profissionais relataram presenciar acidentes escolares que se assemelham com este levantamento, principalmente quando descrevem como mais comuns o sangramento nasal e as 
fraturas. Outro estudo(5) descreveu a queda e entorses como as mais prevalentes

A proposta da realização de uma abordagem teórica e prática, utilizando a observação do local de ensino e de temas sugeridos pelos próprios docentes, intensifica o papel desse profissional na aptidão de identificar situações de risco nesse ambiente. Assim, prevenir o acidente em espaço escolar passa por produzir em toda a comunidade educativa uma cultura de segurança e por tornar a escola um local seguro e saudável(5).

As dificuldades do manejo em casos de acidentes escolares são confirmados na literatura pela deficiência de conhecimentos dos docentes sobre as condutas corretas a serem tomadas nas diferentes situações. Os docentes sentem-se parcialmente preparados para atender situações simples ${ }^{(5)}$; têm dúvidas quanto à gravidade das lesões, não se sentindo preparados para prestar assistência ${ }^{(8)}$, apresentando atitudes inseguras e medo de realizar o cuidado(8), sem saber identificar a melhor conduta a ser tomada(2).

Concluiu-seque os professores, geralmente, têmfacilidade de aprendizado frente às ações educativas dialógicas, quando essas compartilham suas próprias vivências e os consideram atores principais do processo e protagonistas das discussões. Estudos compartilharam experiências aproximadas e tiveram resultados significativos ${ }^{(1,2)}$, enquanto outros também reforçam a importância da realização de capacitação dos profissionais das escolas para contribuir com a educação em saúde que vem ao encontro com a iniciativa da Política Nacional de Redução Morbimortalidade por Acidentes e
Violências do Ministério da Saúde e a Política de Saúde na Escola(3,5,9)

\section{CONCLUSÃO}

O interesse da criança em explorar novas situações, sua potencialidade, novas habilidades e a forma de interação com o ambiente escolar podem ocasionar acidentes quando expostas às ameaças presentes nesse espaço. No levantamento realizado, a estrutura dos ambientes escolares observados apresentou fatores de risco para tais acontecimentos, o que representa a necessidade de investimentos da política de governo em estudos para adequação desses locais, beneficiando a comunidade usuária.

Dessa forma, muitos desses casos podem ser prevenidos e, se vierem a ocorrer, é fundamental o conhecimento dos profissionais envolvidos para a prestação dos primeiros socorros. Foi identificada uma deficiência nesse propósito por parte do educador, que compartilha a maior parte do seu tempo com as crianças dentro da escola. Este estudo comprovou que medidas educativas envolvidas no diálogo podem auxiliar na construção do fortalecimento e aprimoramento dessa prática.

Assim, a fomentação de parcerias entre os profissionais de educação com os da saúde se torna promissora no planejamento de discussões do campo da saúde e sua forma de abordagem no ambiente educacional, auxiliando a construção de novos métodos, estratégias e formas de pensar.

\section{REFERÊNCIAS}

1. Coelho JPSL. Ensino de primeiros socorros nas escolas e sua eficácia. Revista cientifica do ITAPAC On-line [Internet]. 2015 [acesso em 20 fev 2017]; 8(1). Disponivel em: <http://www.itpac.br/arquivos/Revista/76/Artigo_7.pdf>

2. Meireles GOAB. Abordagem de Primeiros Socorros Realizada Pelos Professores em uma Unidade de Ensino Estadual em Anápolis - GO. Ensaios Cienc., Cienc. Biol. Agrar. Saúde [Internet]. 2014 [acesso em 23 fev 2017].v. 18, n. 1, p. 25-30. Disponivel em: <http://www.redalyc.org/ $\mathrm{pdf} / 260 / 26037787004 . \mathrm{pdf}>$

3. Oliveira RA, Junior RL, BORGES CC. Situações de primeiros socorros em aulas de educação física em municipios do sudoeste de goiás. Enciclopédia biosfera. [Internet]. 2015 [acesso em 23 fev 2017]. v.11, n.20; p. 72-77. Disponivel em: <http://www.conhecer.org.br/enciclo$\mathrm{p} / 2015 \mathrm{a} / \mathrm{situacoes}$.pdf>

4. Brozeli EA. Orientações de Primeiros Socorros em Urgência na Escola. [Internet]. 2014 [acesso em 01 jun 2016]. Disponivel em: <http:// www.unifia.edu.br/revista_eletronica/revistas/saude_foco/artigos/ ano2014/primeiros_socorros_naescola.pdf>.
5. Venâncio MAVD. Prevalência dos acidentes em espaço escolar e percepção dos agentes educativos. [Internet]. 2014. [acesso em $23 \mathrm{fev}$ 2017]. Dissertação (Mestrado em Enfermagem Comunitária) - Escola Superior de Saúde de Viseu. Disponivel em: <http://repositorio.ipv.pt/ bitstream/10400.19/2559/1/VENANCIO,\%20Maria\%20Alice\%2OVaranda\%20Duarte\%20-\%20DissertMestrado.pdf>.

6. Brasil, Ministério da Saúde. Protocolos de Intervenção para o SAMU 192 - Serviço de Atendimento Móvel de Urgência. Brasilia: Ministério da Saúde; 2014.

7. Costa WAC et al.Unidade didática de ensino dos primeiros socorros para escolares: efeitos do aprendizado. Pensar a Prática. [Internet] 2015. [acesso em 23 fev 2017]. v. 18, n. 2, p.338-349. Disponivel em. <http://revistas.ufg.br/fef/article/view/30205/18787>

8. Oliveira AS, Lopes AG, Lisboa JM. Campelo DML, Marinho CMM. Araujo LSC. Atuação dos Professores às crianças em casos de acidentes na escola. Rev Interdisciplinar UNINOVAFAPI 2012; 5(3): 26-30.

9. Brasil. Ministério da saúde. Saúde na Escola. 1 ed. Brasilia: Ministério da saúde; 2009. 